\title{
DEPRESSÃO EM DOCENTES: CUIDANDO DE SI PARA CUIDAR DE OUTROS
}

Vanderley Martins dos Santos Psicanalista, professor mestrando em psicologia

\section{RESUMO}

A depressão é condição médica comum, crônica e recorrente. Está frequentemente associada à incapacidade funcional e ao comprometimento da saúde física e mental da pessoa. Ansiedade e depressão é uma das principais causas de afastamento de professores do trabalho, baixos salários e a necessidade de mais de um emprego para completar a renda é uma realidade comum entre os profissionais da educação. Este artigo tem como objetivo geral destacar sobre a depressão em docentes, abordando os motivos e o contexto deste problema. A metodologia aplicada na realização deste estudo pode ser classificada como pesquisa bibliográfica. É importante que o professor conheça suas próprias emoções, conhecer estas emoções envolve necessariamente cuidar da saúde mental e física, assim, cuida de si como um todo, para isso ele precisa estar com profissionais de educação física que proporciona atividades físicas, bem como também psicólogos, que são necessários para ter este melhor conhecimento. Respeitar o seu tempo e aprender a dizer não são dicas valiosas para o professor, que tem como atividade comum pegar muitas atividades se exaustando e cobrando muito de si.

Palavras-chave: Depressão. Educação. Psicologia.

\section{INTRODUÇÃO}

A depressão é condição médica comum, crônica e recorrente. Está frequentemente associada à incapacidade funcional e ao comprometimento da saúde física e mental da pessoa. Desta forma, a depressão tem como característica o transtorno de humor multifatorial que envolve aspectos afetivos, motivacionais, cognitivos e neurovegetativos que devem ser levados em conta em sua avaliação e tratamento (NORONHA JUNIOR, 2015). 
Ansiedade e depressão é uma das principais causas de afastamento de professores do trabalho, baixos salários e a necessidade de mais de um emprego para completar a renda é uma realidade comum entre os profissionais da educação. Em média 45 professores por dia pedem afastamento das salas de aula no Estado de São Paulo, por exemplo, crises de ansiedade e depressão são queixas cada vez mais frequentes. Agressões sofridas dentro das salas de ala estão entre os principais motivos que obrigam os docentes a tirar licença médica e se afastar das escolas.

Este artigo tem como objetivo geral destacar sobre a depressão em docentes, abordando os motivos e o contexto deste problema. Para tanto, os objetivos específicos se voltaram a conceituar a depressão, abordar sobre a depressão em professores e apontar como a psicologia clínica pode auxiliar nos casos de depressão em docentes.

A metodologia aplicada na realização deste estudo pode ser classificada como pesquisa bibliográfica. Para Gil (2010) a pesquisa bibliográfica é desenvolvida com base em material já elaborado, constituído principalmente de livros e artigos científicos.

\section{DEPRESSÃO}

O Brasil ocupa o primeiro lugar no ranking de prevalência da depressão, segundo a OMS (Organização Mundial de Saúde), a expectava é que no mundo $20 \%$ da população possui a doença. A depressão é um fenômeno epidemiológico no mundo atual, pois além de fatores genéticos das causas da depressão entram as situações de estresse e o mundo moderno está cada vez mais estressante, levando a população ao limite. Vale ressaltar como um fator agravante da depressão que os fatos negativos que ocorrem na vida de uma pessoa pressionam a mente muito mais do que os fatos negativos, sendo assim, é comum se recordar muito mais facilmente de coisas ruins que aconteceram do que as coisas boas (SILVA, 2016).

Como fatores de risco pode-se citar o histórico familiar, onde na família já teve algum tipo de diagnóstico de distúrbios depressivos, sendo assim a convivência também pode influenciar no surgimento da depressão. Também os 
transtornos psiquiátricos correlatos são fatores de risco para a depressão, ou seja, quando a pessoa tem algum outro transtorno psiquiátrico, como por exemplo a bipolaridade, onde a pessoa altera entre períodos de humor depressivos rebaixado e períodos de manias (BARROSO et. al, 2015).

Segundo Cybulski e Mansani (2017)

A depressão é considerada a condição mais incapacitante e penosa que existe1. É uma doença complexa, que pode levar a complicações que atingem inúmeras esferas da vida de um indivíduo. No cenário do estudante de Medicina, isto inclui o desempenho acadêmico e a relação médico-paciente (CYBULSKI; MANSANI, 2017, p. 93).

O estresse crônico é um fator determinante para dar início ao quadro depressivo, pois assim são geradas reações químicas no corpo que a longo prazo pode vir a desencadear a depressão. As disfunções hormonais também são fatores que podem vir a desenvolver a depressão, bem como o excesso de peso, sedentarismo, dieta desregrada, entre outros transtornos alimentares (BARROSO et. al, 2015).

Situações de vício, como o cigarro, álcool, drogas, bem como o uso excessivo de internet são capazes de desencadear a depressão. Alguns traumas físicos ou psicológicos, assim como pancadas na cabeça, problemas cardíacos, separação conjugal e enxaqueca crônica, todas estas situações são facilitadoras para a instalação do quadro depressivo, por isso é importante ter cuidado com a saúde mental (OLIVEIRA et. al, 2015).

Também como fatores de risco pode-se citar os distúrbios do sono, quando a pessoa dorme muito ou não consegue dormir, pensamentos negativos que geram desinteresse e desprazer, a baixa autoestima, onde a pessoa tem uma visão negativa sobre si, desleixo com a aparência, onde a pessoa não consegue realizar cuidados comuns do corpo no dia-a-dia, dores físicas no corpo sem motivo aparente, isolamento, rejeição, onde a pessoa muitas vezes costuma ser grosseira com pessoas próximas, mudanças comportamentais bruscas e rejeição a determinados assuntos, quando a pessoa não quer ouvir falar do assunto chegando a sair do local ou fazer algum tipo de grosseria. Sobre isso, Andretta et. al (2018) ressaltam que "os sentimentos negativos sobre si, a 
redução de satisfação nas atividades diárias e o humor deprimido afetam diretamente a qualidade de vida do indivíduo".

Oliveira et. al (2015) ressalta que "a depressão maior é uma das causas que lidera o aspecto de anos de vida ajustados para incapacidade e invalidez. É a principal doença e motivo de inaptidão entre os adolescentes e, globalmente, é a principal causa de doença e deficiência nesta faixa etária".

Se a maioria destes sintomas predominarem por até duas semanas seguidas pode ser diagnosticado a depressão, que é feita através do primeiro acesso do paciente com o psicólogo ou psiquiatra, onde o profissional dará o diagnóstico. O ideal é que a pessoa vá diretamente ao especialista que é o psiquiatra, porém, é possível que o clínico geral faça o diagnóstico e encaminhe para o psiquiatra (BARROSO et. al, 2015).

O psicólogo avalia todos os sintomas mencionados para conseguir mensurar através de uma aplicação de testes, que pode ser por exemplo 0 inventário de Back que irá complementar a visão do profissional a respeito do assunto, onde será possível verificar o nível de ansiedade, dos sintomas depressivos e de desesperança, pois estes fatores sempre estão relacionados, assim, é possível avaliar se o paciente tem uma depressão leve, moderada ou grave (PEREIRA; AZEVEDO, 2016).

No caso de haver o diagnóstico o paciente é encaminhado ao psiquiatra, caso seja um clínico geral ou psicólogo. É comum que alguns pacientes insistam em ser tratados com a psicoterapia somente, procurando o psiquiatra somente em caso de não solução com a psicoterapia. Segundo Lannes (2018) ressalta que os tratamentos para o indivíduo com diagnóstico de depressão comumente utilizadas no cuidado aos indivíduos são: psicoterapia, uso de psicofármacos e estimulação magnética transcraniana.

O psiquiatra também avalia toda a situação do paciente para buscar entender os fatores de risco, bem como os sintomas, assim, com o diagnóstico o psiquiatra entra com a medicação para contribuir com o alívio dos sintomas, porém, o psicólogo sempre será indicado para tratamento paralelo à medicação, considerando que o psicólogo trabalhará a mente do paciente e o psiquiatra trabalhará o corpo, sendo esta união necessária para o sucesso do tratamento do paciente (CYBULSKI; MANSANI, 2017). 
Não se recomenda que o paciente faça somente o tratamento psiquiátrico, pois os sintomas serão tratados, mas à medida em que o medicamento for suspenso os sintomas irão voltar, pois a pessoa não mudou a maneira de pensar, uma vez que ele precisa reaprender a viver e enxergar as coisas de maneira diferente (BARROSO et. al, 2015)

\subsection{SAÚDE MENTAL DOS PROFESSORES}

A depressão atinge 1/3 dos professores, esta é uma estimativa pública de diferentes pesquisas que entendem o que muitos não procuram, ou seja, não são diagnosticados e não procuram ajuda mesmo estando em casos graves de depressão. Isso ocorre devido ao preconceito, onde muitas vezes acontece por parte do próprio docente.

A rotina dos professores é uma das mais exaustivas, devido ao baixo salário, os professores têm mais de um vínculo empregatício, chegando a trabalhar até mesmo 60 horas por semana. As relações de trabalho, baixo salário e total desmoralização do docente é um agravo para a depressão, promovendo o sofrimento e angústia destes profissionais. Reclamar por condições melhores de trabalho é comum em qualquer lugar, seja em empresas privadas ou públicas e o fato do professor não conseguir se colocar o oprime no dia-a-dia. Todas as relações hostis, como cobrança de metas em excesso, ameaças, entre outras, devem ser pensadas na situação tensa que convive o docente constantemente.

A depressão é silenciosa e traz uma soma de problemas apresentando sintomas que não levados em consideração, dentre eles, pode-se citar os medos, crises, estresses, sono, palpitação, desanimo, irritabilidade, esquecimento, fadiga, sentimento de vazio, falta de energia e isolamento. Todos estes são oriundos de relações sociais dicotômicas, conflitos constantes, falta de voz, jornadas excessivas de trabalho, salários baixos, dentre outros, mas todos basicamente da falta de reconhecimento social (LIMA; LEITE, 2016).

Apesar de tudo isso ser sintomas de depressão, ter estes sintomas não significa ter a depressão, a depressão surge quando estes sentimentos são corriqueiros aumentando a sensação de vazio juntamente com todos os sintomas se tornam frequentemente presentes. Respeitar o seu tempo e 
aprender a dizer não são pontos fundamentais para a saúde mental do professor, que normalmente pega muitas atividades para fazer se sobrecarregando e se cobrando de uma forma desgastante e que não promove a saúde mental do mesmo (SILVA; SILVA; LOUREIRO, 2018).

Segundo a organização internacional do trabalho o professor é um dos profissionais mais cometidos pelo estresse do trabalho, o que gera grandes consequências. O professor, independentemente do nível de ensino, está mais suscetível ao adoecimento, independente se este trabalha em empresa pública ou privada. Cada uma destas fases de ensino gera um comprometimento diferente.

Existem algumas consequências do adoecimento mental do professor, uma delas é a perca de sono, onde o professor passa a ter muita insônia não conseguindo dormir normalmente como antes ou ficando muito cansado sentindo sono excessivo. Acontece um esgotamento grande em relação ao trabalho e um aumento de vontade de isolamento social (LIMA; LEITE, 2016).

Em tempo de pandemia e com o enfrentamento do Covide-19 desde 0 mês de março deste ano de 2020, professores são obrigados a sair das salas de aula e em muitos casos são impulsionados a oferecer ensino de dentro de suas residências por meios tecnológicos. Porém, vale ressaltar que para um professor que enfrenta a depressão e já sente à vontade de ficar em isolamento social, este tipo de situação pode ser ainda mais agravante, considerando que este profissional não sairá mais de casa perdendo sua antiga rotina escolar e pessoal se vendo obrigado adaptar-se a uma nova rotina escolar.

Uma das causas mais grave deste adoecimento é a síndrome de Burnout, que é justamente a síndrome do esgotamento do trabalho, não acomete somente professores, mas estes estão entre as profissões que mais são acometidos por esta síndrome, que tem três características principais, o esgotamento e exaustão que gera irritabilidade, cansaço e vontade de se isolar e não frequentar mais o ambiente de trabalho, bem como a questão da indisposição para preparar as atividades da sala de aula, onde o profissional fica indisposto de realizar toda e qualquer atividade referente ao seu trabalho (SILVA; SILVA; LOUREIRO, 2018). 
Uma das características mais importantes é a despersonalização, o que significa que este profissional não tem mais empatia pela emoção do outro e perde a capacidade de se preocupar estando tão inerte em seus problemas que não tem mais vontade e capacidade de entender a emoção do aluno ou colegas de trabalho, onde o professor se torna mais ríspido, sarcástico e irônico, perdendo a paciência com as pequenas coisas que antes ele tinha (COSTA; SILVA, 2019).

Este esgotamento é diferente da depressão e precisa de um diagnóstico do psiquiatra para fazer a avaliação, mas atualmente é uma das maiores causas de afastamento do trabalho e de absenteísmo. Existem algumas situações que o professor deve proporcionar para que ele possa entender e melhorar sua qualidade de vida dentro da sala de aula e do seu trabalho (LIMA; LEITE, 2016).

\section{CONSIDERAÇÕES FINAIS}

É importante que o professor conheça suas próprias emoções, conhecer estas emoções envolve necessariamente cuidar da saúde mental e física, assim, cuida de si como um todo, para isso ele precisa estar com profissionais de educação física que proporciona atividades físicas, bem como também psicólogos, que são necessários para ter este melhor conhecimento. Respeitar o seu tempo e aprender a dizer não são dicas valiosas para o professor, que tem como atividade comum pegar muitas atividades se exaustando e cobrando muito de si. 


\section{REFERÊNCIAS}

ANDRETTA, I. Sintomas de Depressão, Ansiedade e Estresse em Usuários de Drogas em Tratamento em Comunidades Terapêuticas. Rev. Psico-USF, Bragança Paulista, v. 23, n. 2, p. 361-373, abr./jun. 2018. Disponível em: < http://www.scielo.br/pdf/pusf/v23n2/2175-3563pusf-23-02-361.pdf>. Acesso em: maio de 2020.

BARROSO, S. M. et. al. Fatores associados à depressão: diferenças por sexo em moradores de comunidades quilombolas. Rev. Bras. Epidemiol. Abr-jun 2015; 18(2): 503-514. Disponível em: < https://www.scielosp.org/article/ssm/content/raw/?resource_ssm_path $=/ \mathrm{media} /$ assets $/ \mathrm{rbepid} / \mathrm{v} 18 \mathrm{n} 2 /$ pt_1415-790X-rbepid-18-02-00503.pdf $>$. Acesso em: maio de 2020.

COSTA, R; SILVA, N. Níveis de ansiedade e depressão entre professores do Ensino Infantil e Fundamental. Pro-Posições. Campinas, SP. V. 30. 2019.

CYBULSKI, C; MANSANI, F. Análise da depressão, dos Fatores de risco para Sintomas depressivos e do uso de antidepressivos entre acadêmicos do Curso de medicina da universidade Estadual de Ponta Grossa. Revista Brasileira de educação Médica 41, 92-101; 201792. Disponível em: < http://www.scielo.br/pdf/rbem/v41n1/1981-5271rbem-41-1-0092.pdf>. Acesso em: maio de 2020.

GIL, A. C. Métodos e técnicas de pesquisa social. 5. ed. São Paulo: Atlas, 2010.

LIMA, E; LEITE, E. Docência e a depressão: fatores predominantes no processo. Disponível em: https://educere.bruc.com.br/arquivo/pdf2017/24512_12130.pdf. Acesso em: maio de 2020.

NORONHA JUNIOR, M. A. et. al. Depressão em estudantes de medicina. Rev. Med. Minas Gerais. 2015; 25, 562-567562.

OLIVEIRA, F. P. et. al. Sintomas de depressão e fatores intervenientes entre enfermeiros de serviço hospitalar de emergência. Rev. Acta Paul Enferm. 2015; 28(3):209-15. Disponível em: < http://www.scielo.br/pdf/ape/v28n3/1982-0194-ape-28-03-0209.pdf>. Acesso em: maio de 2020.

PEREIRA, M; AZEVEDO, J. Depressão e angústia: modos de expressão na contemporaneidade. Revista da Graduação em 
Psicologia da PUC Minas v. 2, n. 3, jan./jul. 2017 - ISSN 2448-0738.

Disponível em: < seer.pucminas.br>. Acesso em: maio de 2020.

SILVA, E. F. Acompanhamento de pacientes com depressão no território da estratégia saúde da família atalaia no município de Governador Valadares: projeto de intervenção. 2016. Disponível em:

<https://www.nescon.medicina.ufmg.br/biblioteca/imagem/EDINEIAFERNANDA-DA-SILVA.pdf>. Acesso em: maio de 2020.

SILVA, N; SILVA, A; LOUREIRO, S. Burnout e depressão em professores do ensino fundamental: um estudo correlacional. Revista Brasileira de Educação. V. 23. 2018. 